\title{
Medication Abortion and Family Physicians' Scope of Practice
}

\author{
Linda W. Prine, MD, and Ruth Lesnewski, MD
}

Since the founding of family medicine, family physicians have repeatedly defended its scope of practice. The right to provide maternity care, colonoscopy, and surgical procedures has been disputed and defended in many forums. Medication abortion, an office-based service that many family physicians would like to offer to women with unintended pregnancies, is a new addition to this list of contested procedures. Nearly half of all pregnancies in the United States are unintended; of these, approximately half end in abortion. Approximately $35 \%$ of American women have an abortion at some point in their lives. ${ }^{1}$ But many women have difficulty accessing abortion care; $87 \%$ of all counties in the United States have no abortion provider. $^{2}$ When the FDA approved mifepristone in 2000, many observers believed that pro-choice primary care physicians would expand abortion care to underserved communities in the United States. ${ }^{3-6}$ Unfortunately, restrictions in professional liability coverage and insurance reimbursement have hindered this progress. Many family physicians have found that their professional liability insurance does not cover medication abortion. ${ }^{7,8}$

\section{Who Determines the Scope of Family Medicine?}

The American Academy of Family Physicians (AAFP) "maintains responsibility for determining the philosophy, content, and scope of family practice." 9 Family physicians' practices vary widely, influenced not only by an individual physician's training and preferences but also by local demographics,

Submitted, revised, 23 March 2005.

From Beth Israel Residency in Urban Family Practice, Albert Einstein College of Medicine, New York, New York. Conflict of interest: none declared.

Corresponding author: Linda Prine, MD, Associate Professor of Family Medicine, Beth Israel Residency in Urban Family Practice, Albert Einstein College of Medicine, 16 East 16th Street, New York, NY 10003 (e-mail: lindaprine@earthlink.net). hospital privileges, insurance reimbursement, and relationships with other specialists. Although multiple factors determine the range of services that individual physicians provide, the AAFP has resolved that, through the organization's advocacy efforts, its members should retain control over the content of the specialty-that is, its scope. ${ }^{9}$ Because family physicians provide the only medical care in many rural areas of the United States, restricting the scope of family medicine would decrease the care available to many Americans. Without family physicians, $43 \%$ of US counties would meet the criteria for Health Professional Shortage Areas, which means that these areas would have fewer than one primary care physician per 3500 residents. ${ }^{10}$ However, even in some regions with adequate primary care medical staffing, abortion remains unavailable. In many rural areas, women must travel more than 100 miles to end an unintended pregnancy. ${ }^{11}$ The abortion provider shortage has multiple causes. Only a small minority of obstetrics-gynecology and family medicine residency programs offer abortion training, some trained physicians fear antiabortion violence, and other physicians personally oppose abortion. ${ }^{12-14}$

\section{Medication Abortion in Family Medicine: Recent History}

Insurance restrictions have not prevented all family physicians from offering medication abortion. Over the past decade, numerous family physicians have successfully integrated medication abortion into their practice. Before the release of mifepristone, some family physicians provided medication abortion with methotrexate, ${ }^{15}$ and several participated in the US mifepristone trials. Most of these family physicians have liability coverage through their institutional employer rather than individual policies. The National Abortion Federation, the organization representing abortion providers, reports that $18 \%$ of its members are family physicians and $50 \%$ 
are gynecologists. ${ }^{16}$ Numerous articles published in family medicine journals (Table 1) and presentations at family medicine scientific and academic meetings (Table 2) demonstrate that family physicians can safely provide medication abortion and that they consider it within their scope of practice.

During mifepristone's approval process, the FDA considered restricting the medication's use to gynecologists. However, the final approval allows mifepristone to be sold to "physicians who can accurately determine the duration of a patient's pregnancy and detect an ectopic (or tubal) pregnancy." All family physicians receive training in the determination of gestational age and in detection of ectopic pregnancy. Physicians who prescribe mifepristone "must also be able to provide surgical intervention in cases of incomplete abortion or severe bleeding - or they must make plans in advance to provide such care through others." ${ }^{17}$ This language conforms to the way family medicine is

\section{Table 1. Medication Abortion Articles in Family Medicine Journals}

Gold M, Luks D, Anderson MR. Medical options for early pregnancy termination. Am Fam Physician 1997;56:533-8.

Leeman L, Espey E. "You can't do that 'round here": a case study of the introduction of medical abortion care at a University Medical Center Contraception 2005;71:84-8.

Lesnewski R, Prine L, Gold M. Abortion training as an integral part of residency training. Fam Med 2003;35:386-7.

Nothnagle M, Taylor JS. Medical methods for first-trimester abortion. Am Fam Physician 2004;70:81-3.

Prine L. In sickness and health: choosing. Fam Syst Health 2002;20:431-7.

Prine L, Lesnewski R, Berley N, Gold M. Medical abortion in family practice: a case series. J Am Board Fam Pract 2003;16:290-5.

Prine L, Lesnewski R, Bregman R. Integrating medical abortion into a family medicine practice. Fam Med 2003; 35:469-71.

Raymond E, Kaczorowski J, Smith P, Sellors J, Walsh A. Medical abortion and family physicians. Survey of residents and practitioners in two Ontario settings. Can Fam Physician 2002;48:538-44.

Schaff EA, Eisinger SH, Franks P, Kim SS. Combined methotrexate and misoprostol for early induced abortion. Arch Fam Med 1995;4:774-9.

Schaff EA, Eisinger SH, Franks P, Kim SS. Methotrexate and misoprostol for early abortion. Fam Med 1996;28:198-203.

Schaff EA, Stadalius LS, Eisinger SH, Franks P. Vaginal misoprostol administered at home after mifepristone (RU486) for abortion. J Fam Pract 1997;44:353-60.

Winikoff B, Ellertson C, Elul B, Sivin I. Acceptability and feasibility of early pregnancy termination by mifepristonemisoprostol. Results of a large multicenter trial in the United States. Mifepristone Clinical Trials Group. Arch Fam Med 1998;7:360-6.
Table 2. Medication Abortion Presentations at Academic Family Medicine Conferences

STFM National Meetings 2000 to present: 9 workshops, seminars, and research papers on the topic of medication abortion

STFM Northeast Regional Meetings: 1999 to present: 7 workshops, seminars, and research papers on the topic of medication abortion

AAFP National Meetings 2000 to present: 3 workshops and seminars on options counseling for unintended pregnancy which included discussions of using mifepristone in a family medicine setting

practiced: family physicians treat to the extent that they can, and refer to specialists when indicated. Studies have demonstrated that surgical intervention (ie, a uterine aspiration procedure) is needed in only $0.8 \%$ to $5 \%$ of mifepristone abortions. ${ }^{18-20}$

\section{Conclusion}

Medication abortion is not a surgical procedure but rather a treatment process that requires a significant amount of counseling. Assessing the patient's support system, emotional state, and understanding of the process fits squarely within family medicine. Family physicians' extensive training in counseling prepares them well for this service. Perhaps even more important, the skills required for medication abortion are easier to apply in the context of an ongoing relationship between a patient and her family physician.

Medication abortion clearly falls within family physicians' scope of practice. The incidence of complications with mifepristone abortion is extraordinarily low. ${ }^{18,21}$ Providing medication abortion entails less risk than managing a continuing pregnancy. ${ }^{22-24}$ In fact, mifepristone may be less risky to prescribe than the recently released medications for erectile dysfunction. ${ }^{26-29}$ Professional liability carriers seem to have based their decisions regarding insuring family physicians for providing medication abortion on factors far removed from actuarial risk. Perhaps the politically charged nature of abortion plays a role here? In any case, insurance companies' refusal to cover family physicians for medication abortion amounts to an inappropriate restriction of our scope of practiceeffectively impeding American women's access to a much needed service. The AAFP should work with insurance companies and their regulators to resolve this problem. 


\section{References}

1. Alan Guttmacher Institute [homepage on the Internet]. New York: Alan Guttmacher Institute; c2003. [updated 2003 May 7]. State facts about abortion; [about 1 screen]. Available from: http://www.agiusa.org/pubs/sfaa.html.

2. Finer LB, Henshaw HK. Abortion incidence in the United States in 2000. Perspect Sexual Reprod Health 2003;35:16-24.

3. Lerner S. Abortion's new choice. Village Voice 2000 Oct 4; Features:43-8.

4. Koenig JD, Tapias MD, Hoff T, Stewart FH. Are US health professionals likely to prescribe mifepristone or methotrexate? J Am Med Women's Assoc 2000;55:155-60.

5. Joffe C. Medical abortion in social context. Am J Obstet Gynecol 2000;183:10-5.

6. Henry J. Kaiser Family Foundation. A National Survey: views of women's health care providers on medical abortion. Menlo Park (CA): Kaiser Family Foundation; 2000.

7. Joffe C. Roe v. Wade at 30: What are the prospects for abortion provision. Perspect Sexual Reprod Health 2003;35:29-33.

8. Boonstra H. Mifepristone in the United States: status and future. The Guttmacher Report on Public Policy 2002;5:4-7. Available from http://www.guttmacher.org/pubs/tgr/05/3/gr050304.html

9. American Academy of Family Physician [homepage on the Internet]. Leawood (KS): American Academy of Family Physicians; c2004 [updated 2005; cited 2004 Aug 13]. AAFP policy and advocacy: family medicine; [about 2 screens]. Available from: http:// www.aafp.org/x6809.xml.

10. Fryer GE, Green LA, Dovey SM, Phillips RI Jr. The United States relies on family physicians unlike any other specialty. Am Fam Physician 2001;63:1669.

11. Henshaw HK, Finer LB. The accessibility of abortion services in the United States, 2001. Perspect Sexual Reprod Health 2003;35:6-15.

12. Westhoff C, Marks F, Rosenfield A. Residency training in contraception, sterilization and abortion. Obstet Gynecol 1993;81:311-4.

13. Grimes DA. Clinicians who provide abortions: the thinning ranks. Obstet Gynecol 1992;80:719-23.

14. Steinauer J, DePinerest T, Robert AM, Wesfall J, Darney P. Training family practice residents in abortion and other reproductive health care: a nationwide survey. Fam Plann Perspect 1997;29:222-7.

15. Gold M, Luks D, Anderson MR. Medical options for early pregnancy termination. Am Fam Physician 1997;56:533-8.

16. Lichtenberg ES, Paul M, Jones H. First trimester surgical abortion practices: a survey of National Abortion Federation members. Contraception 2001; 64:345-52.

17. Approval letter Mifeprex (mifepristone) tablets [letter on the Internet]. Bethesda (MD): Food and Drug Administration; c2000 [posted 2000 Sept 28; cited 2004 Aug 13]. Available from: http://www.fda.gov/ cder/foi/appletter/2000/20687appltr.htm.

18. Allen RH, Westhoff C, De Nonno L, Fielding SL, Schaff EA. Curettage after mifepristone-induced abortion: frequency, timing, and indications. Obstet Gynecol 2001;98:101-6.

19. Schaff EA, Stadalius LS, Eisinger SH, Frank P. Vaginal misoprostol administered at home after mifepristone for abortion. J Fam Pract 1997;44:353-60.

20. Prine L, Lesnewski R, Berley N, Gold M. Medical abortion outcomes in four family practices. J Am Board Fam Pract 2003;16:290-5.

21. Newhall EP, Winikoff B. Abortion with mifepristone and misoprostol: regimens, efficacy, acceptability and future directions. Am J Obstet Gynecol 2000; 183 Suppl 2:S44-53.

22. Stewart FH, Shields WC, Hwang AC. Presenting health risks honestly: mifepristone, a case in point. Contraception 2004;69:177-8.

23. Elam-Evans LD, Strauss LT, Herndon J, Parker WY, Whitehead S, Berg CJ. Abortion surveillanceUnited States, 1999. MMWR Surveill Summ 2002; 51:1-9, 11-28.

24. Chang J, Elam-Evans LD, Berg CJ, et al. Pregnancyrelated mortality surveillance-United States, 19911999. MMWR Surveill Summ 2003;52:1-14.

25. Morrison H. Sildenafil (Viagra): cardiac risks. CMAJ 2000;163:86-7, 90-1.

26. Wysowski DK, Farinas E, Swartz L. Comparison of reported and expected deaths in sildenafil (Viagra) users. Am J Cardiol 2002;89:1331-4.

27. Egan R, Pomeranz H. Sildenafil (Viagra) associated anterior ischemic optic neuropathy. Arch Opthalmol 2000;118:291-2.

28. Cohen JS. Comparison of FDA reports of patient deaths associated with sildenafil and with injectable alprostadil. Ann Pharmacother 2001;35:285-8. 